\title{
Preventing spinal cord injury following thoracoabdominal aortic aneurysm repair: The battle to eliminate paraplegia
}

\author{
Cenea M. Kemp, MD, ${ }^{\mathrm{a}}$ Zihan Feng, BS, ${ }^{\mathrm{b}}$ Muhammad Aftab, $\mathrm{MD},{ }^{\mathrm{c}}$ and T. Brett Reece, $\mathrm{MD}^{\mathrm{c}}$
}

Thoracoabdominal aortic intervention may be the most complex operation for cardiothoracic surgeons to perform and for patients to tolerate. The most feared complication of extensive thoracoabdominal procedures is spinal cord injury. Although understanding of this injury continues to evolve, surgeons have been able to reduce the incidence of paraplegia significantly over time through the use of multiple adjuncts, including staged aortic repair, maintenance of distal perfusion intraoperatively, management of intraoperative and postoperative hypotension, neuromonitoring, reimplantation of intercostal arteries, drainage of cerebral spinal fluid, intraoperative cooling, and pharmacologic adjuncts. However, significant burdens persist, including increased risk of mortality, increased perioperative hospital stays, increased hospital costs, increased need for rehabilitation admissions following discharge, and the resultant changes in quality of life for both the patients and their families. Further reduction in spinal cord injury, or optimally the elimination of paraplegia altogether, remains the ultimate goal for aortic surgeons performing complex aortic intervention.

\section{SPINAL CORD INJURY: PATHOPHYSIOLOGY}

Spinal cord injury resulting in paraplegia has been described since the introduction of thoracoabdominal surgery. Among Stanley Crawford's original descriptions of open thoracoabdominal repair, he recognized the spinal perfusion implications of ligating all the intercostal and lumbar arteries. ${ }^{1}$ To address this issue, he expanded that intercostal reimplantation was attempted whenever feasible. As numbers accrued with thoracoabdominal aortic aneurysm (TAAA) repair, it became clear that patients in the later described extent II group experienced paraplegia $(>20 \%)$ despite attempts at intercostal reimplantation. ${ }^{2}$ Until the 1990 s, TAAA repairs were approached more commonly with a cut-and-sew method.

\footnotetext{
From the ${ }^{\mathrm{a}}$ Department of Surgery and ${ }^{\mathrm{c}}$ Division of Cardiothoracic Surgery, Department of Surgery, ${ }^{\mathrm{b}}$ University of Colorado School of Medicine, Anschutz Medical Campus, Aurora, Colo.

C.M.K., Z.F., and M.A. contributed equally to this article.

Received for publication Jan 14, 2021; accepted for publication Jan 15, 2021; available ahead of print March 24, 2021.

Address for reprints: T. Brett Reece, MD, Division of Cardiothoracic Surgery, Department of Surgery, University of Colorado School of Medicine, Anschutz Medical Campus, 12631 East 17th Ave, Room 6502, MS C310, PO Box 6511, Aurora, CO 80045 (E-mail: brett.reece@cuanschutz.edu).

JTCVS Techniques 2021;8:11-5

2666-2507

Copyright (C) 2021 Published by Elsevier Inc. on behalf of The American Association for Thoracic Surgery. This is an open access article under the CC BY-NC-ND license (http://creativecommons.org/licenses/by-nc-nd/4.0/).

https://doi.org/10.1016/j.xjtc.2021.01.046
}

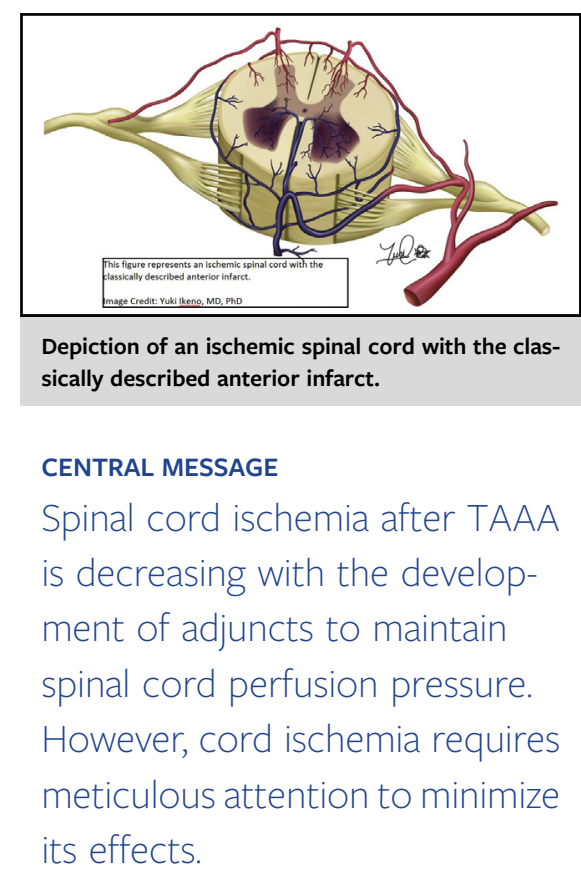

See Commentaries on pages 16 and 18.

Spinal cord injury was believed to be the result of 2 issues: ischemia reperfusion from lower-body ischemia during the case and the loss of direct perfusion for the spinal cord. Despite improvements in perfusion and spinal cord protection techniques, these complications persist. However, paraplegia endures for different reasons than believed at first. As will be discussed, the lumbar prominence remains a watershed after extensive operations, with perfusion through both the intercostal patches and the collaterals above and below the resected area. This watershed will recover, but recovery may not be early enough to prevent irreversible neuron injury. Currently, this slow recovery relative to ischemic tolerance is believed to be the cause of delayed paraplegia. The loss of end arterial perfusion through either intercostal ligation or embolism is believed to be the cause of dense paraplegia evident intraoperatively. Unfortunately, the recovery from this type of injury is negligible. Delayed paraplegia can be reversed in many instances by maneuvers to increase perfusion to the watershed. This transient ischemia does result in an ischemia/reperfusion phenomenon. Much basic science has focused on reducing the burden of this injury, but the most accepted approaches to reducing this injury have been focused on 
limiting exposure to the watershed through systemic and local hemodynamic factors. Both the understanding and practical approaches to limiting the injury once it occurs remain elusive. Current techniques will be reviewed here.

\section{FACTORS ASSOCIATED WITH INCREASED RISK FOR SPINAL CORD ISCHEMIA}

The aneurysm characteristics as well as the approach to the repair can have profound effects on the risk and prevention of paraplegia. These characteristics include the extent of replacement, partitioning of repair, monitoring of neurologic function, and the optimization of spinal cord perfusion. The loss of direct perforators and hypotension relate to paraplegia. Further monitoring of markers of perfusion can be addressed to reduce this instigator of injury.

\section{Predictors of Paraplegia}

Extent of aortic replacement. The most important risk factor associated with spinal cord injury following TAAA repair is the extent of aortic coverage. ${ }^{3}$ Most of the spinal cord blood supply was previously attributed to the artery of Adamkiewicz. It is now known that the spinal cord has a complex blood supply derived from multiple sources, including the intercostal, lumbar, segmental, subclavian, and internal iliac arteries, as well as small arteries contained within the perivertebral tissues and paraspinous muscles. ${ }^{4} \mathrm{~A}$ greater extent of aortic coverage during repair results in more segmental arteries (SA) sacrificed, increasing the risk of spinal cord injury.

Gaudino and colleagues ${ }^{5}$ reviewed studies from 2008 to 2018 on TAAA repair reporting that rates for Crawford extents I, II, III, IV, and V aneurysms were $4.0 \%, 15.0 \%$, $7.0 \%, 2.0 \%$, and $7.0 \%$, respectively. Obviously, the highest rate is observed for Crawford type II aneurysms. In a review of 445 consecutive TAAA repairs, Conrad and colleagues ${ }^{6}$ reported similar findings showing that spinal cord injury occurred more frequently in type I or II than in III or IV (17\% vs $8 \%)$ and identifying extent I or II aneurysms as independent predictors of spinal cord injury.

Staged repair of TAAAs. It has been shown that sacrifice of SA during TAAA results in a significant decrease in spinal cord perfusion pressure (SCPP); however, remodeling of the collateral network takes place over 5 days following SA loss. ${ }^{4,7}$ Based on this, multiple studies have examined the use of staged procedures in TAAA, or replacing separate segments of aorta at disparate operations. ${ }^{8-10}$ These studies have demonstrated a statistically significant decrease in the rate of postoperative paraplegia in both animal and human models. ${ }^{8,9}$ Staged procedures done in a hybrid manner using thoracic endovascular aortic repair followed by open repair of the abdominal component have also demonstrated a reduction in the incidence of postoperative paraplegia. ${ }^{10}$

\section{Procedure Management}

Left heart bypass (LHB) and distal perfusion. LHB is a widely used adjunct during TAAA repair that decreases the risk of spinal cord injury by shunting oxygenated blood from the left heart to the distal circulation thus maintaining blood flow to the tissue distal to the aortic crossclamp. In a retrospective analysis performed by Coselli and LeMaire, ${ }^{11}$ patients with an extent I or II TAAA underwent open repair with or without LHB. There was no significant difference between the LHB and non-LHB patients with an extent I aneurysm. Those patients with an extent II TAAA who underwent repair with LHB had a significantly reduced rate of paraparesis and paraplegia (4.8\%) compared with those patients who underwent repair without LHB (13.1\%), emphasizing the importance of maintaining distal perfusion, especially in more extensive aneurysms. ${ }^{11}$

In addition to LHB, perfusion to the spinal cord can be maintained via sequential aortic clamping. Sequential clamping allows for immediate reperfusion of reimplanted SA limiting the overall ischemic period for individual segments of the spinal cord during the repair. To the best of our knowledge, no large trial has been performed to assess the efficacy of sequential clamping for reducing the risk of spinal cord injury during open TAAA repair.

Neuromonitoring and early injury detection. The current methods for monitoring neurological function include motor-evoked potentials (MEP), somatosensory-evoked potentials (SSEP), and near-infrared spectrometry (NIRS). Due to its rapid response to blood pressure and cerebrospinal fluid changes, neuromonitoring enables early detection of neurologic deficits.

Banga and colleagues ${ }^{12}$ demonstrated decreases in MEPand SSEP-predicted immediate spinal cord injury that allowed for the quick implementation of a standardized protocol to optimize spinal cord perfusion and restore lower extremity blood flow. Intraoperative monitoring of MEP as a guide to adequate spinal cord perfusion has been shown to reduce the acute paraplegia rate to $4.1 \%$ in extent I or II TAAA. $^{13}$

NIRS, an easily applicable noninvasive tool for continuous monitoring of regional hemoglobin oxygen saturation, has also been used in the early detection of spinal cord injury. Boezeman and colleagues ${ }^{14}$ validated the association of regional hemoglobin oxygen saturation with MEP monitoring and demonstrated the feasibility of NIRS to surveil the hemodynamic changes in oxygenation of the paraspinal region during and after TAAA repair.

Although neuromonitoring has gained popularity, there is no consensus regarding which neuromonitoring modality generates the most benefit. Fok and colleagues showed MEP is more useful than SSEP at predicting paraplegia. 
Most patients whose MEP dropped and remained below threshold had immediate permanent neurologic deficit, whereas loss of SSEP had little association with permanent neurologic deficit. ${ }^{15}$ Further studies are needed to identify the ideal neuromonitoring strategy in preventing spinal cord injury and paraplegia in TAAA repair.

\section{Intraoperative Intervention}

Intraoperative hypotension. SCPP is a function of the mean arterial pressure minus the cerebrospinal fluid pressure. Thus, a reduced mean arterial pressure results in a reduction in the SCPP. Intraoperative hypotension or sustained hypotension have been identified as independent risk factors for spinal cord injury following TAAA repair. ${ }^{3,6}$ This phenomenon was also identified in thoracic endovascular aortic repair, specifically correlating with iliac rupture being a risk factor for spinal cord injury due to hypotension in early feasibility studies. ${ }^{16}$ Figure 1 illustrates an ischemic spinal cord following the classically described anterior infarct.

SCPP maintenance. As previously discussed, the spinal cord has a dense bloody supply. According to the Collateral Network Concept, the presence of multiple contributing sources allows for compensation when flow from 1 of the blood supply sources is compromised. ${ }^{17}$ Complete SA sacrifice in a pig model by Etz and colleagues ${ }^{4}$ demonstrated an $80 \%$ to $100 \%$ increase in the diameter of the anterior spinal artery and epidural arcades, significant increase in density of the paraspinous vasculature with increased organization of the vessel alignment, as well as a substantial decrease in flow resistance within 5 days of total SA sacrifice.

Endovascular aortic aneurysm repair results in occlusion of the intercostal/lumbar arteries, providing a good clinical example of the importance of the collateral network in maintaining adequate spinal cord perfusion. Eagleton and colleagues $^{18}$ described immediate onset of symptomatic spinal cord ischemia in $73 \%$ of patients who either already had known occlusion of at least 1 hypogastric artery before undergoing endovascular repair or who had intraoperative

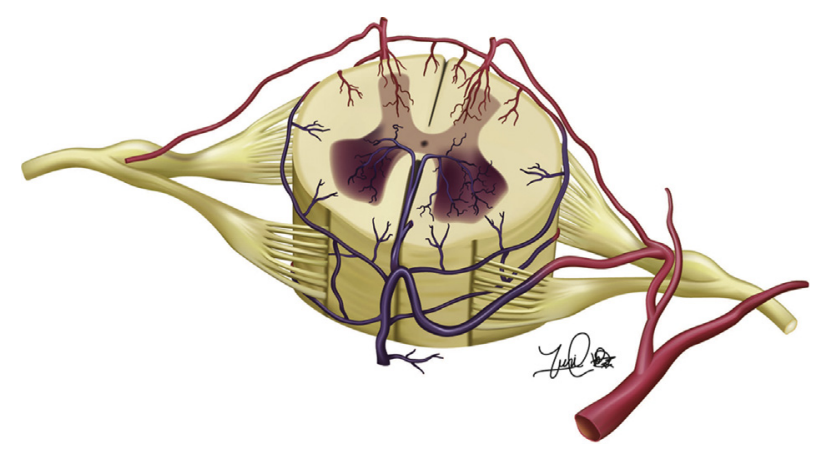

FIGURE 1. A cross-sectional view of the spinal cord following an anterior cord infarction. Image created by Yuki Ikeno $\mathrm{MD}, \mathrm{PhD}$. Used with permission. occlusion of the left subclavian or 1 of the hypogastric arteries. In comparison, the onset of acute postoperative paraplegia, paraparesis, and sensory deficits occurred in $24 \%$ of patients who had bilateral patency of the subclavian and hypogastric arteries.

Intercostal artery reimplantation. Reimplantation of the intercostal arteries is a way of maintaining the complex blood supply network to the spinal cord. However, this adjunct remains controversial. Afifi and colleagues ${ }^{19}$ conducted a 13-year review of all descending thoracic aneurysm and TAAA repairs at their facility. Selective T8 to T12 intercostal artery reimplantation was carried out based on their protocol and loss of intraoperative MEPs. Findings demonstrated a 1.3-fold increase in the odds of developing paraplegia, both early and delayed, for each intercostal artery ligated from T8 to T12 even if intraoperative MEPs remained intact. This suggests routine reimplantation of intercostal arteries, at least at the level of T8 to T12, could be a useful adjunct in reducing the rates of early and delayed paraplegia following TAAA repair. The authors also noted a minimal increase in operative time (1-2 minutes per vessel) associated with intercostal artery reattachment. ${ }^{19}$

Intraoperative and postoperative cerebrospinal fluid pressure measurement and drainage. In addition to the dense blood supply spinal cord perfusion also depends on the SCPP as previously discussed. Early mouse studies done by McCullough and colleagues ${ }^{20}$ postulated that drainage of cerebrospinal fluid could serve as a useful adjunct in TAAA aneurysm repair to reduce the risk of spinal cord ischemia suggesting that elevated cerebrospinal fluid pressures impair spinal cord perfusion. Since that time, multiple retrospective studies evaluating cerebrospinal fluid drainage have been suggestive of potential benefit in the reduction of postoperative paraplegia and paraparesis. ${ }^{21}$ A randomized controlled trial published by Coselli and colleagues $^{21}$ randomized 145 patients undergoing extent I or II TAAA repair to either a cerebrospinal fluid drainage group or a noncerebrospinal fluid drainage group with the primary end points of death, paraplegia, and paraparesis. Findings demonstrated an $80 \%$ reduction in the relative risk of paraplegia and paraparesis. In those patients who initially did not undergo cerebrospinal fluid drainage but who developed postoperative neurologic deficits, the study also demonstrated a gradual improvement in neurologic function in $50 \%$ of patients with delayed placement of a spinal drain and cerebrospinal fluid drainage.

Epidural cooling. Hypothermia during circulatory arrest is a well-known and widely used method of protecting end organs during TAAA repair. Cambria and colleagues ${ }^{22}$ developed a method for direct epidural cooling via the instillation of $4^{\circ} \mathrm{C}$ normal saline through an epidural catheter, reducing the incidence of paraplegia/paraparesis to $7 \%$. Neither method—epidural cooling versus hypothermia 
during circulatory arrest-has been proven superior. Although there are whispers of a device that can facilitate this process rather than having 2 drains to cool, it has not been introduced in a useable fashion that these authors are aware of currently.

Maintenance of postoperative mean arterial pressure. Although the exact mechanism of delayed paraparesis and paraplegia following TAAA repair has not been elucidated, postoperative hypotension is believed to play a role. ${ }^{23}$ Serial neurologic exams allow for early detection and intervention in suspected spinal cord ischemia. The close monitoring and maintenance of postoperative mean arterial pressure has been shown to aid in the recovery of neurologic function. Cheung and colleagues ${ }^{23}$ demonstrated complete resolution of neurologic deficits in 5 out of 8 patients who developed delayed onset paraplegia by increasing the mean arterial pressure to a minimum of $90 \mathrm{~mm} \mathrm{Hg}$ at the onset of neurologic deficits; the mean arterial pressure was subsequently increased an additional $5 \mathrm{~mm} \mathrm{Hg}$ until the neurologic deficits stabilized or function was recovered. Three of the 8 patients recovered partial function with residual neurologic deficits. Cerebrospinal fluid drainage was also used as a postoperative adjunct, so it is uncertain if maintaining an elevated mean arterial pressure alone aided in the recovery of or improvement in the postoperative neurologic function. Pharmacological attenuation of spinal cord protection. The least discussed, and potentially the least proven, approach to prevention of spinal cord injury is pharmacologic protection. Little has been adopted on a wide scale with regard to injury prevention using medications, yet a vast literature exists on basic science and small case series about the utility of medications for prevention of neuron injury or death. These pharmacologic agents range from local vasodilators intended to improve flow to watershed vessels, vasopressors that are crucial in the rapid elevation of mean arterial pressure to maintain the SCPP, to medications that attempt to reduce cellular injury through reduction of either apoptosis or excitotoxicity in the affected neurons. $^{23-25}$ Other agents are believed to aid in the prevention of ischemia reperfusion injury, which might play a key role in delayed spinal cord injury. ${ }^{24,25}$ Widespread adoption has not been realized because pharmaceutical companies do not want to support trials for these types of medications in procedures that are relatively uncommon with significant morbidity and mortality. Table 1 provides examples of potential medications that may attenuate spinal cord injury.

\section{CONCLUSIONS}

Spinal cord ischemia in TAAA repair has been shown to be associated with the extent of the aneurysm, intraoperative/postoperative hypotension, and prior history of neurologic deficits. Multiple methods have been developed to monitor spinal cord health and many adjuncts are known
TABLE 1. Examples of potential pharmacologic agents in the attenuation of spinal cord injury ${ }^{24,25}$

\begin{tabular}{|c|c|}
\hline Mechanism of action & Suggested agent(s) \\
\hline Local vasodilator & Papaverine \\
\hline Vasopressor & $\begin{array}{l}\text { Epinephrine, norepinephrine, } \\
\text { phenylephrine }\end{array}$ \\
\hline $\begin{array}{l}\text { Reduction of neuronal } \\
\text { excitotoxicity }\end{array}$ & $\begin{array}{l}\text { Steroids (methylprednisone), riluzole, } \\
\text { magnesium sulfate, basic fibroblast } \\
\text { growth factor, } \\
\text { dehydroepiandrosterone, } \\
\text { dehydroepiandrosterone sulfate }\end{array}$ \\
\hline Prevention of apoptosis & Minocycline \\
\hline $\begin{array}{l}\text { Prevention of ischemia } \\
\text { reperfusion injury }\end{array}$ & Statins \\
\hline $\begin{array}{l}\text { Antioxidant/ } \\
\text { anti-inflammatory }\end{array}$ & $\begin{array}{l}\text { Minocycline, methylprednisone, statins, } \\
\text { N-acetyl-cysteine, iloprost, } \\
\text { minocycline, allopurinol }\end{array}$ \\
\hline $\begin{array}{l}\text { Ischemic } \\
\text { preconditioning }\end{array}$ & Dexmedetomidine, anesthetic gases \\
\hline
\end{tabular}

to decrease the risk of spinal cord injury during TAAA repair. Although these adjuncts have been effective in reducing the risk of paraplegia compared with the initial operative outcomes, further work must be done to identify the exact mechanism for spinal cord injury and develop a consistent and reproducible strategy to further decrease, and perhaps eliminate, the risk of spinal cord injury in the setting of TAAA repair.

\section{Conflict of Interest Statement}

The authors reported no conflicts of interest.

The Journal policy requires editors and reviewers to disclose conflicts of interest and to decline handling or reviewing manuscripts for which they may have a conflict of interest. The editors and reviewers of this article have no conflicts of interest.

\section{References}

1. Crawford ES. Thoraco-abdominal and abdominal aortic aneurysms involving renal, superior mesenteric, celiac arteries. Ann Surg. 1974;179:763-72.

2. Crawford ES, Snyder DM, Cho GC, Roehm JO Jr. Progress in treatment of thoracoabdominal and abdominal aortic aneurysms involving celiac, superior mesenteric, and renal arteries. Ann Surg. 1978;188:404-22.

3. Miranda V, Sousa J, Mansilha A. Spinal cord injury in endovascular thoracoabdominal aortic aneurysm repair: prevalence, risk factors and preventive strategies. Int Angiol. 2018;37:112-26.

4. Etz CD, Kari FA, Mueller CS, Brenner RM, Lin HM, Griepp RB. The collateral network concept: remodeling of the arterial collateral network after experimental segmental artery sacrifice. J Thorac Cardiovasc Surg. 2011;141:1029-36.

5. Gaudino M, Khan FM, Rahouma M, Naik A, Hameed I, Spadaccio C, et al. Spinal cord injury after open and endovascular repair of descending thoracic and thoracoabdominal aortic aneurysms: a meta-analysis. J Thorac Cardiovasc Surg. May 13, 2020 [Epub ahead of print].

6. Conrad MF, Crawford RS, Davison JK, Cambria RP. Thoracoabdominal aneurysm repair: a 20-year perspective. Ann Thorac Surg. 2007;83:S856-92. 
7. Etz CD, Di Luozzo G, Zoli S, Lazala R, Plestis KA, Bodian CA, et al. Direct spinal cord perfusion pressure monitoring in extensive distal aortic aneurysm repair. Ann Thorac Surg. 2009;87:1764-74.

8. Geisbüsch S, Stefanovic A, Koruth JS, Lin H-M, Morgello S, Weisz DJ, et al. Endovascular coil embolization of segmental arteries prevents paraplegia after subsequent thoracoabdominal aneurysm repair: an experimental model. $J$ Thorac Cardiovasc Surg. 2014;147:220-6.

9. Etz CD, Zoli S, Mueller CS, Bodian CA, Di Luozzo G, Lazala R, et al. Staged repair significantly reduces paraplegia rate after extensive thoracoabdominal aortic aneurysm repair. J Thorac Cardiovasc Surg. 2010;139:1464-72.

10. Hawkins RB, Mehaffey JH, Narahari AK, Jain A, Ghanta RK, Kron IL, et al. Improved outcomes and value in staged hybrid extent II thoracoabdominal aortic aneurysm repair. J Vasc Surg. 2017;66:1357-63.

11. Coselli JS, LeMaire SA. Left heart bypass reduces paraplegia rates after thoracoabdominal aortic aneurysm repair. Ann Thorac Surg. 1999;67:1931-4.

12. Banga PV, Oderich GS, Reis de Souza L, Hofer J, Cazares Gonzalez ML, Pulido JN, et al. Neuromonitoring, cerebrospinal fluid drainage, and selective use of iliofemoral conduits to minimize risk of spinal cord injury during complex endovascular aortic repair. J Endovasc Ther. 2016;23:139-49.

13. Jacobs MJ, Mess W, Mochtar B, Nijenhuis RJ, Statius van Eps RG, Schurink GW. The value of motor evoked potentials in reducing paraplegia during thoracoabdominal aneurysm repair. J Vasc Surg. 2006;43:239-46.

14. Boezeman RP, van Dongen EP, Morshuis WJ, Sonker U, Boezeman EHJF, Waanders FGJ, et al. Spinal near-infrared spectroscopy measurements during and after thoracoabdominal aortic aneurysm repair: a pilot study. Ann Thorac Surg. 2015;99:1267-74.

15. Fok M, Jafarzadeh F, Sancho E, Abello D, Rimmer L, Howard C, et al. Is there any benefit of neuromonitoring during descending and thoracoabdominal aortic aneurysm repair? Innovations (Phila). 2015;10:342-8.

16. Hughes GC, Daneshmand MA, Swaminathan M, Nienaber JJ, Bush EL, Husain AH, et al. "Real world" thoracic endografting: results with the Gore TAG device 2 years after U.S. FDA approval. Ann Thorac Surg. 2008;86:1530-8.
17. Griepp RB, Griepp EB. Spinal cord perfusion and protection during descending thoracic and thoracoabdominal aortic surgery: the collateral network concept Ann Thorac Surg. 2007;83:S865-92.

18. Eagleton MJ, Shah S, Petkosevek D, Mastracci TM, Greenberg RK. Hypogastric and subclavian artery patency affects onset and recovery of spinal cord ischemia associated with aortic endografting. J Vasc Surg. 2014;59:89-94.

19. Afifi RO, Sandhu HK, Zaidi ST, Trinh E, Tanaka A, Miller CC, et al. Intercostal artery management in thoracoabdominal aortic surgery: to reattach or not to reattach? J Thorac Cardiovasc Surg. 2018;155:1372-8.e1.

20. McCullough JL, Hollier LH, Nugent M. Paraplegia after thoracic aortic occlusion: influence of cerebrospinal fluid drainage. Experimental and early clinica results. J Vasc Surg. 1988;7:153-60.

21. Coselli JS, LeMaire SA, Köksoy C, Schmittling ZC, Curling PE. Cerebrospina fluid drainage reduces paraplegia after thoracoabdominal aortic aneurysm repair: results of a randomized clinical trial. J Vasc Surg. 2002;35:631-9.

22. Cambria RP, Davison JK, Carter C, Brewster DC, Chang Y, Clark KA, et al Epidural cooling for spinal cord protection during thoracoabdominal aneurysm repair: a five-year experience. J Vasc Surg. 2000;31:1093-102.

23. Cheung AT, Weiss SJ, McGarvey ML, Stecker MM, Hogan MS, Escherich A et al. Interventions for reversing delayed-onset postoperative paraplegia after thoracic aortic reconstruction. Ann Thorac Surg. 2002;74:413-21.

24. Nardone R, Pikija S, Mutzenbach JS, Seidl M, Leis S, Trinka E, et al. Current and emerging treatment options for spinal cord ischemia. Drug Discov Today. 2016; 21:1632-41.

25. Ghincea CV, Ikeno Y, Aftab M, Reece TB. Spinal cord protection for thoracic aortic surgery: bench to bedside. Semin Thorac Cardiovasc Surg. 2019;31:713-20.

Key Words: thoracoabdominal aortic aneurysm, thoracoabdominal aortic aneurysm repair, spinal cord ischemia, paraplegia, spinal cord protection 